\title{
HOST ACCEPTANCE AND OVIPOSITION BEHAVIOUR OF SOLITARY WASP, ANISOPTEROMALUS CALANDRAE (HOWARD) (HYMENOPTERA : PTEROMALIDAE), A PARASITOID OF STORED GRAIN PESTS
}

\author{
K.N. Ahmed*, C. K. Roy, J.L. Munshi, E.A. Zenat and S.K. Ghose ${ }^{1}$ \\ BCSIR Laboratories, Dhaka, Qudrat-e-Khuda Road, Dhanmondi, \\ Dhaka-1205, Bangladesh
}

\begin{abstract}
The host acceptance and oviposition behaviour of the ectoparasitoid, Anisopteromalus calandrae (Howard) (Hymenoptera : Pteromalidae) was observed on unexposed (hidden) and exposed host of Sitophilus oryzae (L.) and Rhyzopertha dominica (F.) under laboratory conditions. The egg-laying behaviour was accomplished in eight phases in hidden hosts of S. oryzae i.e., inside wheat kernels but it was much shorter having five steps in those of exposed hosts. Average total time taken by a mated $A$. calandrae in unexposed host (inside wheat kernels) during different oviposition sequences was 55 minutes. On the other hand, average total time taken by a mated $A$. calandrae in exposed host of $S$. oryzae during oviposition sequences was 91.1 minutes. A. calandrae preferred fully developed S.oryzae grubs rather than half- grown pre-pupae and early pupae in exposed condition. Generally, eggs were laid on or near S. oryzae host larvae or pupae inside wheat kernel because of ectoparasitic nature of A. calandrae. More eggs are deposited in case of $S$. oryzae hosts at the abdominal region dorsally, sometimes eggs were laid on the meta-thoracic segment dorsally but rarely eggs were laid on late $S$. oryzae pupae prior to adult transformation. Oviposition by a mated A. calandrae female parasitoid was influenced by the host's size and shape on exposed as well as unexposed (within seed kernel) conditions. Generally, the $3^{\text {rd }}$ and the $4^{\text {th }}$ instar larvae and pre-pupae of $S$. oryzae were preferred for egglaying in exposed condition. The parasite did not lay eggs on naked $R$. dominica larvae or pupae.
\end{abstract}

Key words: Host, acceptance, air position behaviour, solitary WASA. stored grain best

\section{INTRODUCTION}

The females of $A$. calandrae always keep themselves busy in finding and selecting potential or suitable hosts for oviposition. Host acceptance is an essential process for determining the host specificity of the parasite related to different proper stimuli. In a true sense host selection depicts the innate behavior of a parasitic species. The manner in which hosts is selected involves a series of consecutive behavioral phases (Williams 1951, Doutt 1959, Wilson et al. 1974, Strand and Vinson 1983) which ultimately terminates in the oviposition with provisions of the security of the developing progeny. Although not host specific, A. calandrae, is an ectoparasite of the rice weevil, Sitophilus

*Author for correspondence: <knahmed2010@yahoo.com>. ${ }^{1}$ Nayabazar Degree College, Keraniganj, Dhaka, Bangladesh.

(c) 2018 Zoological Society of Bangladesh DOI: http://dx.doi.org/10.3329/bjz.v46i2.39054 
oryzae (L.)prefers to lay egg on or near the $4^{\text {th }}$ instar larvae and prepae by inserting its extended ovipositor. Of the many hosts so far reported, S. oryzae is most preferred. Host detection, acceptance and oviposition by A. calandrae on hosts hidden inside grain kernels may be differentiated into eight sequential activities such as host encounter, drumming, adoption of drilling posture and tapping, probing drilling, host feeding, oviposition and marking and discrimination (Wilson et al. 1974). Oviposition behavior of mated and virgin females have been noticed to differ to certain extent in alive or dead host choice and long or short duration of egglaying process respectively. The present work describes the host acceptance and egg-laying behaviour of A. calandrae females toward various host stages of S.oryzae larvae. The role of receptors used by mated females in host finding and oviposition was also observed.

\section{MATERIAL AND METHODS}

Sitophilus oryzae larvae and pupae were reared in stored wheat having moisture content of $12-14 \%$ in rectangular plastic containers $(8 \mathrm{~cm} \times 15 \mathrm{~cm} \times$ $25 \mathrm{~cm}$ ) at a constant temperature of $27 \pm 1^{\circ} \mathrm{C}$ and $65 \pm 5 \%$ R.H. Each container was covered by fine muslin and fastened with a rubber band. Host-infested seeds aged $14-20$ and 21 - 25 days were used assuming to contain the $3^{\text {rd }}-4^{\text {th }}$ instar larvae and prepupae- puape, respectively as mentioned by Sharifi and Mills (1971). This was however, verified and confirmed through dissections of the infested seeds. For comparison of the host acceptance oviposition on $R$. dominica as host was also observed. For this purpose, $R$. dominica (F.) larvae and pupae were reared in stored wheat as described by Zaz et al. (1982). A huge number of $A$. calandrae parasitoid were mass reared in the laboratory on the $4^{\text {th }}$ instar larvae, pre-pupae and pupae of $S$. oryzae. Only average sized mated female parasites were used in this experiment that had emerged within a 24-hour period and fed honey-water solution for the next 24 hours. Adult female parasites after standardization were allowed to parasitize egg-laying purpose.

Observations on host acceptance and oviposition behaviour were maintained in small Petri dishes ( $5 \mathrm{~cm}$ in diam.) each containing 20 suitable host infested wheat kernels along with some non-infested seeds. Exposed S. oryzae larvae and pupae of equal sample size were also kept in Petri dishes in a similar manner to record the behavioral events on exposed hosts. The sequence of host acceptance and oviposition behaviour were carefully noted. Time occupied for each event was based on first host encounter and subsequent activities culminating to oviposition by a given female. Observations made on each of 30 mated and 30 virgin females were taken into consideration in the final analysis of the behavioral events. The study was conducted at an average room temperature of 
$30 \pm 1^{\circ} \mathrm{C}$ and $70 \pm 5 \%$ R.H. from April to June, 2017 in the Pest Control Section, BCSIR Laboratories, Dhaka.

\section{RESULTS AND DISCUSSION}

\section{A. Host acceptance and oviposition behavior on hidden host}

Eight distinct behavioral events were exhibited by $A$. calandare females in response to its hosts, S. oryzae hidden inside wheat kernels. The sequences, however, found to overlap to some extent and its time spent for each event is shown in Table 1.

Table 1. Average time taken by a mated $A$. calandrae in unexposed $S$. oryzae host (inside wheat kernels) during different oviposition sequences

\begin{tabular}{lccc}
\hline Steps & $\begin{array}{c}\text { Number of } \\
\text { observation }\end{array}$ & $\begin{array}{c}\text { Mean time } \\
\text { (minutes) }\end{array}$ & Sd \pm SE \\
\hline Host encounter & 30 & 1.8 & $0.2 \pm 0.03$ \\
Drumming & 30 & 3.8 & $0.5 \pm 0.07$ \\
Adoption of drilling posture and & 30 & 7.9 & $0.5 \pm 0.09$ \\
trapping & 30 & 4.8 & $0.3 \pm 0.07$ \\
Probing & 30 & 17.8 & $1.67 \pm 0.10$ \\
Host feeding & 30 & 14.4 & $0.7 \pm 0.10$ \\
Drilling & 30 & 2.7 & $0.4 \pm 0.07$ \\
Oviposition & 30 & 1.8 & $0.2 \pm 0.04$ \\
Marking and discrimination & -- & 55.0 & -- \\
\hline
\end{tabular}

(i) Host encounter: Soon after release into the experimental container the female parasite wandered for some time, then paused for a while when came within approximately of about $1.5 \mathrm{~mm}$ to a seed. The egg-laying female investigated the presence of host inside the wheat kernel by antennal contact slowly and probing with the ventral side of the club of its down-bent geniculate antennae. It also travelled around the entire wheat kernel for host recognition and if found unsuitable, moved to another kernel in search of a potential host. Average time taken by A. calandrae females in the unexposed host to encounter was about 1.8 minutes (Table 1).

(ii) Drumming: The mated female parasitoid next started continued examination by drumming over the entire kernel by the club of her down-bent antennae. During each drumming event, the parasite moved over the host containing seeds both in clockwise and counter clockwise directions. Prior to parasitization, the parasite extends and retracts its ovipositor from $2-3$ times during the last half of drumming. 
(iii) Adoption of drilling posture and trapping: After completion of antennal drumming, the parasitoid comes enclose contact to the substrate (kernel) just over the hidden host by the club of antennae. The parasite confirms host recognition by assuming drilling posture and tapping its abdominal tip for $2-3$ seconds. If the host stage appears unsuitable, the parasite passes to another host kernel for suitable host finding. During tapping by the abdominal tip, the antennae touch the host kernel, the wings were held erect, curves its body at an angle of about $90^{\circ}$, forelegs were drawn forward, middle legs assume perpendicularly and the hind legs were held apart but remaining over the seed surface.

(iv) Probing: Before probing abdominal tip was withdrawn from the host substrate, wings were in horizontal position, the forelegs were extended forward, body was curved at an angle of about $90^{\circ}$ to the substrate, the mouth parts were directed downwards and the forelegs were rubbed with the mandible frequently. The abdominal tip was then rotated slowly, the ovipositior extended nearly $2 \mathrm{~mm}$ to gain leverage for drilling. The ovipositor was then inserted vertically over the host body.

(v) Host feeding: After adoption of drilling posture and exhibiting tapping behavior, the insect then scratched the seed coat just over the seed surface by its mandible, remaining silent for 2 - 3 minutes and then rubbed the entire abdomen with metatarsi. During the act of scratching, the clubs of the downbent antennae kept in contact with the kernel. It also clean its mandible by rubbing with the kernel. A. calandare next starts host feeding by making a feeding tube (Ghani and Sweetman 1955, DeBach 1964) and sucks the fluid for nearly 20 minutes at different intervals to obtain protein for continued egg production.

(vi) Drilling: Due to hardness and compactness of the seed coat of the kernel over the hidden host, drilling appeared to be the most essential event during act of oviposition for adult female parasitoids. During drilling, the ovipositor acts as a drill to pierce the host or the material surrounding the host. It also serves to inject venom to the host. During the process of drilling the entire body of parasite is rotated slowly and the ovipositor thrust within the seed for nearly 30 seconds. The antennae initially moved keeping in touch with the host substrate and these withdrawn from the kernel surface. The wings kept horizontal and motionless. The whole process of drilling in order to prepare oviposition site requires 10 - $13 \mathrm{~min}$. Ovipositor is inserted deeply up to the broad base, i.e., third valvulae for touching and piercing the host. After drilling, the abdominal tip inserted into the drilling site for a while and then moved apart about $3-5 \mathrm{~mm}$ from the drilling site but not leaving the host infested kernel. 
The thrusts made by the ovipositor on the host larvae were observed on the thoracic region dorsally as 3 - 5 dot like reddish spots.

(vii) Oviposition: After drilling, when the oviposition site ready, the female pushes the ovipositor (terebra) deeply through the drilling hole and makes 5 - 7 turns of abdominal tip to and fro on both sides (Fig. 1) and shivered its body vigorously and an egg laid at this moment. The whole process of oviposition and host acceptance behaviour occupied 55 - 60 minutes but the deposition of egg took only 2 - 3 minutes when the oviposition site was found suitable. The female slight elevated her wings and thoracic region before termination of oviposition. A. calandare female generally deposits only one egg per host during single egglaying event which was ascertained by dissecting 100 parasitized host larvae and pupae.

(viii) Marking and discrimination: After oviposition, a female A. calandrae withdrew the ovipositor, raised its head and abdomen within 45 seconds. Then the egg-laying female wandered about or walked over the entire surface, i.e., egglaying area of the kernel containing the host, marking and discriminating with its outstretched antennae for $1-2$ minutes. Discrimination is defined as a process of sensing with the ovipositor or antennae an allelo-chemical left by a female on the host larvae or pupae (Coats 1976). The ability to discriminate or recognize an oviposited host seed is confirmed by by the fact that, the ovipositioning female generally does not lay more than single egg per host larva or pupa. Following completion of marking and discrimination, the female left the oviposition site and proceed to another host containing wheat kernel for further oviposition.

\section{B. Host acceptance and oviposition behavior on exposed host}

The host acceptance and oviposition behavior of mated A. calandrae in case of exposed hosts exhibits marked differences. This behavior may be effected into five discreet steps: host encounter, drumming and tapping, drilling, host feeding and oviposition. The sequences as follows:

(i) Host encounter: Mated A. calandrae female visually recognized the presence of a host larva when she approached approximately $2-3 \mathrm{~mm}$ near to it. Host encounter by the parasite was hastened by host movement and host size. Generally they were more attracted to the 4 th instar larvae and prepupae because these hosts exhibit constant motion by squeezing their bodies.

The egg-laying female suddenly grips the host larva and walks over it for about 1minute. It was interesting to observe that the parasite also moved with the host larvae in gripping position. While gripping, the parasite holds the host body by its legs. This process lasts for nearly 3 minutes (Table 2). 
Table 2. Average time taken by a mated A. calandrae in exposed host of $\mathbf{S}$. oryzae during oviposition sequences

\begin{tabular}{lccc}
\hline Steps & $\begin{array}{c}\text { Number of } \\
\text { observations }\end{array}$ & $\begin{array}{c}\text { Mean time } \\
\text { (minutes) }\end{array}$ & Sd $\pm \mathrm{SE}$ \\
\hline Host encounter & 30 & 3.1 & $0.2 \pm 0.12$ \\
Drumming and tapping & 30 & 3.5 & $0.1 \pm 0.05$ \\
Drilling & 30 & 25.8 & $0.1 \pm 0.06$ \\
Host feeding & 30 & 59.2 & $1.1 \pm 0.49$ \\
Oviposition & 30 & 0.50 & $0.2 \pm 0.08$ \\
Total & -- & 91.1 & -- \\
\hline
\end{tabular}

(ii) Drumming and tapping: This event were accompanied by antennal contact and tapping by abdominal tip. By drumming, the parasitoid realized whether the host larvae were alive or not. Usually the mated female rejects a dead host larva but virgin female often laid unfertilized egg within a very short time. After the drumming was completed, the parasite probed the host by its abdominal tip for 2 - 3 times dorsally at the thoracic and abdominal regions.

(iii) Drilling: Generally, the ovipositor was inserted dorsally at the third thoracic segment of the S. oryzae host larvae and pupae (Fig. 1), antennae were drawn upward and were kept motionless. The abdomen was rotated 3-4 times before the penetration of ovipositor was completed. Head was held slightly downbent at an angle of about $90^{\circ}$ to the host. Before withdrawing the ovipositor, the antennae touched the host larvae. This entire process for paralyzing the prey for the first time lasted for nearly 7 minutes (Table 1). A. calandrae female pushes its ovipositor (terebra) deeply through the drilling hole (Fig. 3).

(iv) Host feeding: After displaying drilling behaviour, the parasite started to show remarkable and interesting biological phenomenon termed as host feeding which is characteristics of some hymenopteran especially the pteromalids (DeBach 1943). The parasitoid exhibits host feeding behavior at the puncture wound made by the thrust of her ovipositor and making a feeding tube (Ghani and Sweetman 1955).

(v) Oviposition: Exposed 4rth instar larvae and pre-pupae of S. oryzae are preferred for oviposition. No eggs were laid on the exposed $R$. dominica (F.) larvae or pupae when supplied. Oviposition was initiated after paralyzing the host and feeding. The beginning of egg-laying was featured by sudden raising and shivering of its abdomen. Then the ovipositing female extended its ovipositor slowly keeping her body almost motionless. The whole process of egg-laying occupied nearly 1.5 hours including host feeding period of nearly 1 hour (Table 2). With the terebra of ovipositor exposed, the egg was deposited by the female within 15 - 20 seconds and release of the egg could be seen with naked eye (Fig. 
4) and the terebra was retracted into the third valvulae prior to the withdrawal of ovipositor.

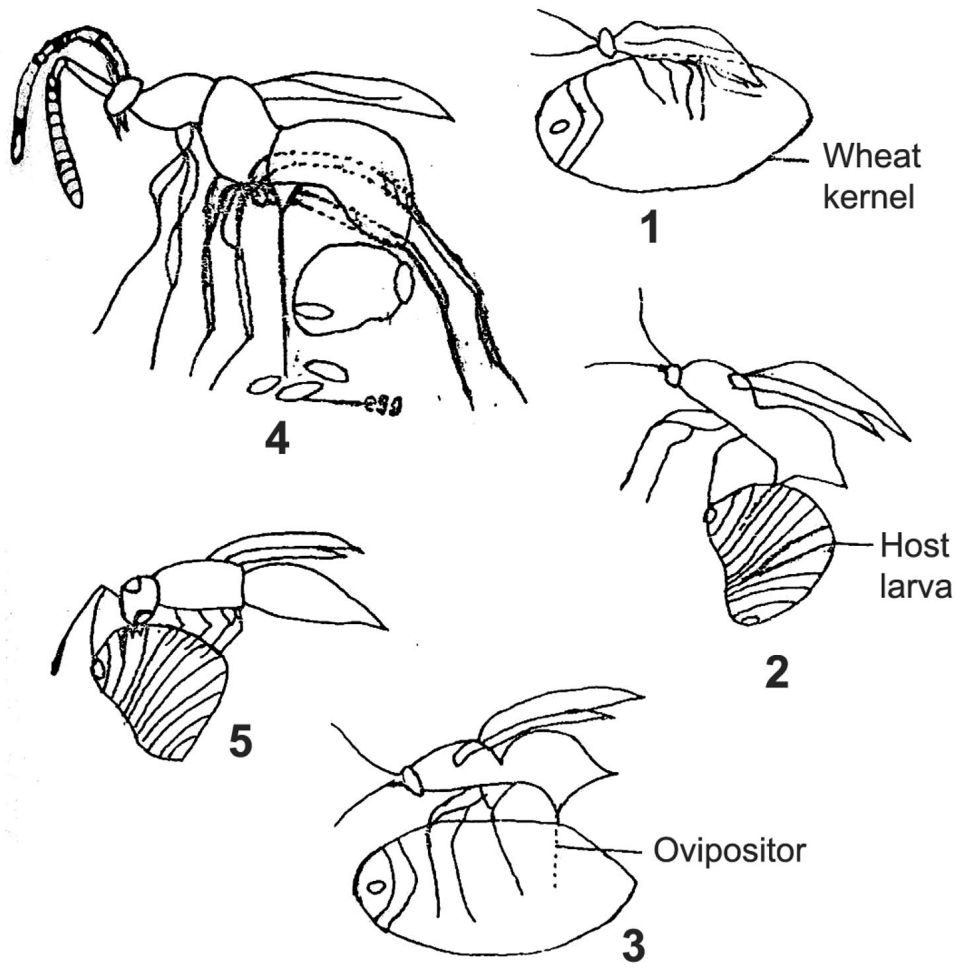

Figs 1-5. 1. Female drilling the wheat kernel containing the host, S. oryzae during oviposition. 2. Insertion of oviposition of $A$. calandrae in the $3^{\text {rd }}$ thoracic segment dorsally during the act of drilling on exposed S. oryzae. 3. A. calandrae female pushes ovipositor (terebra) deeply through the drilling hole. 4 Egglaying on or near the exposed host with extended terebra by $A$. calndrae. 5. Host- feeding by female A. calandrae on the exposed larva of S. oryzae.

The eggs are generally placed near the anal area of the abdomen dorsally or ventrally and 2 - 3 eggs were laid in a single exposed $4^{\text {th }}$ instar larva. A maximum of 5 eggs were laid at different locations of the host body. Among the 5 eggs deposited, one was placed on anal, one at mid-ventral abdominal region, one at ventral thoracic portion and the remaining two were located $2-3 \mathrm{~mm}$ apart from larva. It is evident from the observation that $A$. calandrae laid eggs on both the exposed and the unexposed (within whet kernel) host larvae and pupae of $S$. oryzae but it never oviposited on exposed $R$. domonica larvae or pupae when tested in various ways. Egg is deposited from the $1^{\text {st }}$ day up to the $16^{\text {th }}$ day of adult life of the mated female though it survived upto 18 - 19 days at an average room temperature of $30^{\circ} \mathrm{C}$. An increased rate of oviposition was observed during the $1^{\text {st }}$ week (Fig. 3) and egg laying greatly reduced during last 3 
days of oviposition. Fig. 2 shows insertion of ovipositor of $A$. calandrae in the $3^{\text {rd }}$ thoracic segment dorsally on the exposed S. oryzae larva.

(vi) Host size and shape: It was observed that oviposition by mated $A$. calandrae female was influenced by the shape of the host on exposed as well as unexposed (within seed kernel) conditions. The $3^{\text {rd }}$ and the $4^{\text {th }}$ instar larvae and prepupae of $S$. oryzae were preferred in case of $R$. dominica in unexposure condition only. The parasite did not lay eggs on naked R.dominica larvae or pupae. Chatterji (1955) mentioned that A. calandrae females laid eggs on mature grubs and fresh pupae of S. oryzae and Bruchus analis F. both in exposed and unexposed conditions. Ghani and Sweetman (1955) observed that the females of A.calandrae preferred fully developed S.oryzae grubs rather than half grown pre-pupae and early pupae in exposed condition. They reported that if the host grub was too small, the food supply was exhausted and the parasite died out if the young grubs are attacked, the parasites that develop on them are small in size. Okamoto (1971) reported that $A$. calandrae females parasitized $3^{\text {rd }}$ to $4^{\text {th }}$ larval instars or pupal stage of the host, Callosobruchus chinensis (L.). According to Wilson et al. (1974), the average number of eggs laid by a ichneumonid parasitoid, Campoletis sonorensis in mobile and immobile host larvae of Heliothis virescensi (F.) (Lepidoptera : Noctuidae) were : mobile-living 1.5; immobile-living 5.2; and immobile dead 6.6 which indicated that host sound and movement are essential for host acceptance and oviposition by $C$. sonorensis . The present observation on host acceptance and oviposition behaviour of $A$. calandrae also supports this view, i.e., the host acceptance and oviposition behaviour is based on host size and shape only. Flanders (1944) reviewed the olfactory responses of parasitic Hymenoptera in relation to their mass production generally, eggs are laid on or near $S$. oryzae and $R$. dominica host larvae and pupae inside wheat kernel because of ectoparasitic nature of A.calandrae. More eggs are deposited in case of S. oryzae hosts at the region of abdomen dorsally, sometimes eggs are laid on the meta-thoracic segment dorsally but rarely eggs are laid on late $S$. oryzae pupae prior to adult transformation.

For oviposition on $R$. dominica hosts, mature larvae and fresh pupae were preferred. Generally, eggs were laid ventrally between hind legs of larvae and dorsally to the pupae of $R$. dominica.

According to Khan and Anwarullah (1970), A. calandrae females deposited eggs on the exterior of the grub or in close proximity to it. Chatterji (1955) found that this parasite parasitized larvae and fresh pupae of $R$. dominica and eggs laid singly on the body surface of the host or very near to it. The number of eggs varied one to ten per day depending on the atmospheric temperature and the number of hosts available, he added. 
During the present study, it was observed that mated female A. calandrae exhibited eight behavioural events for host acceptance of its host S.oryzae. According to Strand and Vinson (1983), the host acceptance behaviour of Telenomus virescens (F.) consists of seven discreet steps; host encounter, drumming, adoption of drilling posture, probing, drilling, oviposition accounted for $81 \%$ of the host acceptance time. In the present study, it was observed that drilling required 14.4 minutes and adoption and drilling posture and tapping 7.9 minutes for $A$. calandrae mated females in unexposed $S$. oryzae host (Table 2). Compactness of seed coat over the host hidden inside the kernel is also a factor for increase or reduction of handling time (Heong 1981). It was observed that handling time was nearly 55 minutes in case of the $4^{\text {th }}$ instar $S$. oryzae larvae inside wheat kernel but it approximately 35 minutes inside rice (husk) kernel containing the host similar stage. Due to softness of seed coat of rice kernel, handling time of gypsy moth pupae by the parasite, Brachymeria intermedia (Nees) (Hymenoptera : Chalcididae), increased with increasing host size.Because, male gypsy moths are smaller and less defensive toward attacking parasite than the females, per cent parasitism was greater for the males. The time required for the host feeding by A. calandrae mated females on unexposed host of $S$. oryzae was 17.8 minutes and on the exposed host, the time required for host feeding took nearly 59 minutes. The host feeding was accompanied by repeated tapping by the abdominal tip and thrusting of the ovipositor by the parasite at an alternate manner. Host feeding in pteromalid wasp, Habrocytus cerealellae has previously been described in detail by Fulton (1933). Superparasitism was observed in A. calandrae. This phenomenon involves the presence of more than one individual in one host individual implying a condition adverse to normal development of all or some of the parasite individuals concerned (Simmonds 1943). Super-saturation could be induced by confining many mated female parasites with a few or limited hosts (S. oryzae or R. dominica).

While conducting observations on the host acceptance and oviposition , it was interesting to note that occurrence of some aggressive or territorial behavior for the same host in the females of A. calandrae. This behavior was exhibited by some females for the occupation of same oviposition site in both exposed and unexposed host. Occurrence of this trait has not yet been in other pteromalid parasite by any author. A mated female which already laid egg on a naked S. oryzae $4^{\text {th }}$ instar larva and is engaged in further egg-laying activity, is often approached by another female to lay eggs on the same host. Then, the former female showed aggressive behaviour by displaying rapid antennal movements and adopting a posture that threatened the new comer. This even happened when sufficient host larvae or pupae were available nearby. After 
exhibiting this sort of peculiar behavior, the two rival females may stay on over the host for a while, the newcomer usually leaves after 2 - 3 minutes without egg-laying. Two just laid eggs were found destroyed during this sort of aggressive or territorial behavior for oviposition. A maximum number of 5 eggs laid on a single exposed S.oryzae hosts although eventually only one adult successfully emerged. Strand and Vinson (1983) reported the presence of more than one female in Telenomus heliothidis Ashmead (Hymenoptera : Scelionidae) on host, Heliothis virescens (F.) (Lepiodptera :Noctuidae) however, none did elicit any aggressive or territorial behaviour. Females do not try to guard or protect oviposited eggs from conspecific ones. Eberhard (1975) mentioned that female scelionid wasps exhibited aggressive behaviour. Rothschild (1970) reported that females of Cryone flavipes (Ashmead) (Hymenoptera: Scelionidae) an egg parasite of the rice earbug, Leptocorisa oratorius (F.) (Hemiptera : Alydidae) showed aggressive or territorial behaviour.

Some different were noted in the probing behaviour among mated and virgin females. The mated female parasite although probed dead S. oryzae host by tapping her abdomen for several times, did not pierce the host and left it without oviposition. Williams (1971) reported that the mated female endo-parasitoid, Physcus seminotus encounters a healthy host, the parasite remains motionless usually $1-2$ min but sometimes as long as 7 minutes, while single egg is placed in the hosts body cavity. But if ovipositor encounters a mummified host, Aulacaspis tegalensis beneath the scale, a prolonged and exhausted probing of the mummy cavity follows and not piercing the host larva. After 20 hours of emergence, a mated of $A$. calandrae laid eggs on the exposed $4^{\text {th }}$ instar healthy and alive larvae. They preferred the $4^{\text {th }}$ instar and prepupae rather than pupae and other early stage larvae. The act of egg-laying took nearly 2 minutes. During observation, a mated A. calandrae was seen to oviposit 2 eggs within 5 minutes interval. Mated female does not oviposit in the dead or mummified host and her behaviour appears deliberate and rational. The virgin females on other hand, generally prefers mummified $S$. oryzae host larvae for oviposition instead of alive hosts. She repeated attacks the same mummy inserting and re-inserting the ovipositor which is of shorter duration than those of a mated female and laying 2 or 3 unfertilized eggs.

The eggs laid by $A$. calandrae virgin females are smaller in size and less elongated than those eggs laid by mated females. A one-day old virgin female was found to probe the same mummy 2 - 3 times in rapid succession and less time was required for oviposition, i.e., 1 egg was laid within 1 minute. Superparasitism, therefore, often results when a virgin female finds an optimum host site for unfertilized eggs, with a consequent wastage of eggs. Virgin female 
does not exhibit any wise or discreet behaviour during egglaying. During present study, marking and discrimination is observed during oviposition behavior in mated A.calandrae female only in unexposed hosts ( $S$. oryzae or $R$. dominica) laying only a single egg per host individual generally. But this kind of marking and discrimination behaviour was not found to occur when the parasite depositing egg on exposed hosts. According to Coats (1976), a high level of discrimination during oviposition was displayed by ptreomalid parasite, Muscidifurax zaraptor females. A statistical evaluation of the degree of discrimination exhibited by M.zaraptor females parasites permitted rejection of null hypothesis that female parasites oviposited randomly in fly puparia. They exhibited avoidance behaviour against parasitized hosts and seldom laid more than one egg on pupa $\left(\chi^{2}=87.0\right.$, d.f. $\left.=4, \mathrm{p}>0.005\right)$.

Receptor site selection: Efforts were made to locate the receptor organs associated with host searching and oviposition in A. calandare. Eye although most important in photo-receptor, is effective in host searching only when the insect reaches very close to it. Chemo - and thingmoreceptor seem to be most important and play significant role in the detection of the most important and play significant role in the detection of the host as well as providing necessary stimuli for oviposition. It was found that antennectomy or removal of the antennae, prevented females of $A$. calandare (both mated and virgin) from host finding and oviposition indicating that the antennae are utmost necessary receptor organ for searching host. In almost all the phases of host searching behavior, the female utilizes antennae in many different ways and the organ is held in different fashion indicating sensory applications of its bristles and hairs. Wilson et al. (1974) described similar result on ichneumonid parasite, Campoletis sonorensis (Cameron) that antennectomy or removal of the antennae, in combination with removal of other receptor organs, prevented females of $C$. sonorensis from searching for and egg-laying in host larvae. On the other hand, removal of only the tarsi did not prevent females from locating and attempting to oviposit in host larvae or pupae but movement of the parasite to different host containing kernel become much slower and only a few eggs are laid. The ovipositor certainly possesses sensory receptors, which can detect not only the suitable of the host, but can also perceive whether a host is dead or alive.

\section{LITERATURE CITED}

CHATTERJI, S. 1955. Studies on the biology of Aplastomorpha calandrae [nsecta: Hymenoptera: Chalcididae] parasitic on some storage pests. Proceedings Zoological Society of London, Part-B, 8: 11-23.

COATS, S.A. 1976. Life cycle and behavior of Muscidifurax zaraptor (Hymenoptera: Pteromalidae). Annals Entomological Society of America 69: 772-780. 
DEBACH, P. 1943. The importance of host feeding by adult parasites in the reduction of host population. The Journal of Economic Entomology 36: 647-658.

DEBACH, P. 1964. Biological control of Insect Pests and weeds. Chapman \& Hall, London, 844 p.

DOUTT, R.L . 1959. The biology of parasitic Hymenoptera. Annals Review of Entomology 34:161-182.

EBERHARD,W.G. 1975. The ecology and behavior of sub-social pentatomid bug and two scelionid wasp, strategy and counter in a host and its parasites. Smithsonian Contributory Zoology p. 205.

FLANDERS, S.E. 1941. Peculiar habits of beneficial insects. California Citro 26: 206.

FLANDERS, S.E. 1942. Metaphycus helvolus, an encyrtid parasite of the black scale. The Journal of Economic Entomology 35: 690-698.

STRAND, M.R., VINSON, S.B. 1983. Host acceptance behavior of Telenomus heliothidis (Hymenoptera : Scelionidae) toward Heliothis virescens (Lepidoptera : Noctuidae). Annals Entomological Society of America 76: 781-785.

ROTHSCHLID, G.H.L.1970. Cryone flavipes (Ashmead) (Hymenoptera : Scelionidae), an egg parasite of the rice earbug. Leptocorsia oratorius ( Fabricius) (Hem. : Alydidae). Entomophaga 15: 21.

FLANDERS, S.E. 1944. Diapause in the parasitic Hymenoptera. The Journal of Economic Entomology 37: 408-411.

FULTON, B.B. 1933. Notes on Habrocytus cerealellae, a pasasite of the Angoumois grain moth. Annals Entomological Society of America 26: 536-552.

GHANI, M.A., SWEETMAN, H.L. 1955. Ecological studies on the granary weevil parasite, Alastomorpha calandrae( Howard). Biologia (Pakistan) 1: 115-139.

HEONG, .K.L. 1981. Searching preference of the parasitoid, Anisopteromalus calandrae for different stages of the host, Callosobruchus maculatus in the laboratory. Research Population Ecology 23: $177-191$.

Williams, J.R. 1951. The factors which promote and influence the oviposition behavior of Nemeritus canescens (Grav. (Ichneumonidae: Ophionidae). Proceedings Royal Society of London. A. 26: 40-58.

WILSON, D.D., RIDGWAY, R.L., VINSON, S.B. 1974. Host acceptance behavior of the parasitoid , Campoletis sonorensis (Hymenoptera : Ichneumonidae). Annals Entomological Society of America 67: 271-274.

ZAZ, G.M., BHARDWAJ, S.C. and YADAVA, C.P.S. 1982. Relative susceptibility of some wheat varieties to the lesser grain borer, Rhizopertha dominica Fabricius. Indian J. Ent. 44: 77-82. 